ORIGINAL ARTICLE-

Volume 12 Issue 12020

DOl: 10.21315/eimj2020.12.1.4

ARTICLE INFO

Submitted: $12-10-2019$

Accepted: 16-02-2020

Online: 10-04-2020

\section{Drawbacks in the Implementation of an Integrated Medical Curriculum at Medical Schools and Their Potential Solutions}

\author{
Ihab Shafek Atta ${ }^{1,6}$, Mohamed Atta El-Hag ${ }^{2}$, Salma Ihab Shafek ${ }^{3}$, \\ Hasan S. Al-Ghamdi ${ }^{4}$, Thamer H. Al-Ghamdi ${ }^{5}$ \\ ${ }^{1}$ Pathology Department, Faculty of Medicine, Assuit, Al-Azhar \\ University, EGYPT \\ ${ }^{2}$ Department of Biophysics, Faculty of Science, Cairo University, \\ EGYPT \\ ${ }^{3}$ Faculty of Medicine, Cairo University, EGYPT \\ ${ }^{4}$ Internal Medicine Department, Faculty of Medicine, Albaha \\ University, SAUDI ARABIA \\ ${ }^{5}$ Department of Surgery, Faculty of Medicine, Albaha University, \\ SAUDI ARABIA \\ ${ }^{6}$ Pathology Department, Faculty of Medicine, Albaha University, \\ SAUDI ARABIA
}

To cite this article: Atta IS, El-Hag MA, Ihab Shafek S, Al-Ghamdi HS, Al-Ghamdi TH. Drawbacks in the implementation of an integrated medical curriculum at medical schools and their potential solutions. Education in Medicine Journal. 2020;12(1): 29-42. https://doi.org/10.21315/ eimj2020.12.1.4

To link to this article: https://doi.org/10.21315/eimj2020.12.1.4

\begin{abstract}
This study aims to explore the shortcomings in the implementation of an integrated medical curriculum to recommend solutions to overcome them. The study included 284 participants, including 220 medical students from different medical schools (Albaha University, Al-Azhar University and Cairo University), 52 faculty members and 12 administrative members. A well-formed questionnaire containing both qualitative and quantitative components was designed to evaluate the main aspects of the integrated curriculum. The quantitative items were scored on a Likert scale of one to five, and an independent $t$-test was used to analyse the results. The major pitfalls reported from the students were that the integrated curriculum is more stressful, a lot number of courses, the consecutive arrangement of the courses and a high number of assessments. The major pitfalls reported from the faculty members include missing many subject areas, limited cooperation among disciplines, students can pass the course without achieving the minimum requirements in each discipline, students can leave out some disciplines according to their weight in the course, and they can, therefore, pass the programme without identifying their shortcomings in each discipline separately. The major pitfalls reported from administrative staff includes staff resistance to student-centered activity and the costs of catering to a problem-based learning environment and providing additional equipment. The present findings point to the need for clear policy charts by the administration, the implementation of a faculty development programme, well-equipped teaching/learning rooms and learning resources, in order to improve the efficiency of implementation of the integration programme.
\end{abstract}

Keywords: Integration drawbacks, Medical curriculum, Student-centered learning, Self-directed learning

Dr. Ihab Shafek Atta, M.D, Ph.D. Pathology, Faculty of Medicine, Assuit, Al-Azhar University, 71524, Egypt | Email: Ihab.bassyouny@azhar.edu.eg 


\section{INTRODUCTION}

Many medical schools all over the world have been integrating their medical sciences curricula. At some of these schools, the change was abrupt and did not fulfill the criteria for the implementation of the integrated curriculum. As an integrated curriculum depends mainly on studentcentered learning, its implementation requires specialised equipped teaching and learning rooms along with well-trained faculty members, but unfortunately, most of these schools have reported that their efforts have been hampered by a lack of these facilities. These limitations have, in turn, affected the achievement of the intended learning outcomes in all domains of Bloom Taxonomy $(1,2)$. Many studies have reported the feedback of the students about the integrated curriculum (3-6) such as Wilkerson et al. (3), Shankar et al. (4), and Lam et al. (5) found that the student feedback was positive for the integrated curriculum, while Thompson et al. (6) found no difference between the discipline-specific curriculum and the integrated curriculum. Most of these studies highlighted the positive feedback for the integrated curriculum $(7,8)$, but some of them have reported the disadvantages of the curriculum (9). Importantly, the majority of these studies did not investigate the negative feedback related to incorrect implementation in specific situations.

In response to some of the drawbacks that emerged through an investigative periodic curricular evaluation at different medical schools including Albaha School of Medicine (ABSM) (10-13), an improvement action plan was created to provide a solution to these limitations. The first step is to identify the major issues that interfere with curriculum implementation especially in the newly integrated medical schools. The purpose of this research was to identify these drawbacks and recommend a solution to minimise their effects.

\section{MATERIALS AND METHODS}

This study was undertaken with the ethical approval of the ethical committees and after obtaining the written permission from all participants. This study included a total of 284 participants including 220 $(77.5 \%)$ medical students, 52 (18.3\%) faculty members and $12(4.2 \%)$ ABSM administrative members (see Appendix). The 220 medical students were representing the following medical schools: $160(72.7 \%)$ students from ABSM and 60 (27.3\%) students from Al-Azhar and Cairo medical schools. The 52 faculty members were representing $61 \%$ of the whole faculty member in ABSM, giving their experience from their different origin medical schools that have implemented the integration in the past five years. The 12 ABSM administrative members were representing the $75 \%$ of the total administrative staff of ABSM. This cross-sectional study used a valid, reliable, well-structured questionnaire to evaluate the integration of the medical curriculum with a special focus on its limitations from the perspective of students, faculty and administrative members. The questionnaire was fulfilled by students of all academic years, faculty members and administrative staff. The faculty members were from different schools and different countries, and, therefore, their experiences with integration varied. Each of them had a range of experience that allowed them to estimate the process of integration in their previous schools and compare it with the process in the current school. The questionnaire was designed to explore their attitudes and opinions about the implemented integrated curriculum. The questionnaire was developed by a board comprising associates from different disciplines and medical education. The questions were prepared and modified methodically by the didactic professionals, in order to ensure the validity of the questionnaire. A pilot study was performed on two disconnected clusters: the first cluster represented faculty elements and the second cluster represented students at all levels. The results obtained from both 
clusters were alike, and this confirmed that the questionnaire was consistent, reliable and valid (10). The questionnaire was composed of both qualitative and quantitative components. The qualitative items were scored on a Likert scale of one to five according to the level of satisfaction (11-14). In the qualitative component, the respondents were required to write comments about various features of the integrated curriculum in terms of its strengths and limitations. An independent $t$-test was carried out for analysing the quantitative data derived from the questionnaire. $P$ values $\leq 0.05$ were considered to indicate statistical significance.

\section{RESULTS}

The responses to the quantitative components of the questionnaire revealed that the number of faculty members who were strongly satisfied or satisfied with the teaching strategies, the number of teaching/ learning hours per day, and student-centred activity was significantly lower than the corresponding number of students $(P<$ $0.05)$, while the number of students who were strongly satisfied or satisfied was significantly lower when it came to the number of credit hours assigned for each programme, the sequence of the courses, the learning objectives and the assessments $(P<0.05)$. There was no significant difference in the satisfaction levels with regard to the number of courses and learning resources. The data are shown in detail in Table 1.

The responses in the qualitative part of the questionnaire revealed that most of the students found several aspects of the integrated curriculum to be stressful: the number of credit hours applied for a whole programme, the number of courses, the consecutive arrangement of the courses, and the high number of assessments including quizzes, objective structured practical exam/ objective structured clinical exam (OSPE/ OSCE), clinical exams and final exams for each course. In particular, the assessments were often scheduled in the middle of other ongoing courses, and as a result, the exams were often too close together or had a maximum interval of one or two days. They also reported that there was no gap between the courses, the learning/teaching hours were long, some teaching tools were missing, some subject areas overlapped and the boundary between disciplines was unclear. Subject areas often overlapped when it came to the teaching strategy and tools too. For example, the same learning objective was often met by different tools such as lectures, seminars and problem-based learning. The students also reported that there was often a bias in the assessment of self-directed learning by the faculty members, there were too many learning objectives for each subject and there was a shortage of handouts for lectures and learning resources. All the major comments of the students are summarised in Table 2.

According to the qualitative data obtained from the faculty members, integration requires many pieces of equipment and a well-equipped skill lab, it is not suitable for large groups of students, many subject areas are missing, there is limited cooperation among disciplines, some subject areas cannot be covered fully in the allocated 50 minutes, it is more stressful than traditional learning and students can pass the course without achieving the minimum requirements in each discipline (i.e., a student can pass the musculoskeletal system course without achieving the minimum requirement in pathology). With the integrated curriculum, students can leave out some disciplines according to their weight in the course, and they can, therefore, pass the programme without identifying their shortcomings in each discipline separately. The assessment of self-directed learning, in general and problem-based learning, in particular, by a tutor or facilitators shows a bias in most instances, depending on the nature of the tutor and their disciplines. Additionally, management of the problem-based learning session may be tutor directed: that is, a member of the pathology faculty may focus on the pathology aspect of a topic more than 
the other aspects and may spend most of a session discussing the pathogenesis of a condition, for example, acute inflammation. Some of the faculty members also reported that they had not implemented the basic roles for self-directed learning: that is, the faculty selects the theme at the start of the lesson and does not monitor the students during the steps of the self-directed learning process. Most of their timetables are crowded with activity, and there is no time to spare for some activities that may be affected by unexpected conditions such as bad weather, which leads to sudden student absenteeism. All the major limitations described by the faculty members are summarised in Table 3.
The administrative staff also reported some issues that may interfere with the implementation of the integration system. Some of these include staff resistance to student-centred activity and the costs of catering to a problem-based learning environment and providing additional equipment such as printers, copiers, scanners, etc. Further, the extra time that some employees required to meet complete the long learning hours and the large number of exams each week may be a burden to the administration. There were also some issues that students reported with recording on the electronic recording system. All the major pitfalls of the integrated curriculum mentioned by the administrative members are summarised in Table 4.

Table 1: Data from the quantitative component of the questionnaire used to measure student and staff satisfaction with the integrated approach

\begin{tabular}{|c|c|c|c|c|c|c|c|}
\hline Item & Target & $\begin{array}{c}\text { Strongly } \\
\text { satisfied } \\
n(\%)\end{array}$ & $\begin{array}{c}\text { Satisfied } \\
n(\%)\end{array}$ & $\begin{array}{c}\text { Neutral } \\
n(\%)\end{array}$ & $\begin{array}{c}\text { Dissatisfied } \\
n(\%)\end{array}$ & $\begin{array}{c}\text { Strongly } \\
\text { dissatisfied } \\
n(\%)\end{array}$ & $\begin{array}{c}\text { Independent } \\
t \text {-test }\end{array}$ \\
\hline \multirow{2}{*}{$\begin{array}{l}\text { Credit hours } \\
\text { for each } \\
\text { programme }\end{array}$} & Student & $106(48.1)$ & $54(24.5)$ & $26(11.8)$ & $16(7.2)$ & $18(8.1)$ & \multirow[b]{2}{*}{$0.00274^{*}$} \\
\hline & Faculty & $30(57.6)$ & $16(30.7)$ & $3(5.7)$ & $2(3.8)$ & $1(1.9)$ & \\
\hline \multirow{2}{*}{$\begin{array}{l}\text { Number of } \\
\text { courses }\end{array}$} & Student & $110(50.0)$ & $62(28.1)$ & $17(7.7)$ & $17(7.7)$ & $14(6.3)$ & \multirow{2}{*}{0.1770} \\
\hline & Faculty & $12(23.0)$ & $31(59.6)$ & $4(7.6)$ & $3(5.7)$ & $2(3.8)$ & \\
\hline \multirow{2}{*}{$\begin{array}{l}\text { Sequences of } \\
\text { the courses }\end{array}$} & Student & $120(54.5)$ & $63(28.6)$ & $16(7.2)$ & $13(5.9)$ & $8(3.6)$ & \multirow{2}{*}{$0.03960^{*}$} \\
\hline & Faculty & 32 (61.5) & $15(28.8)$ & $3(5.7)$ & $1(1.9)$ & $1(1.9)$ & \\
\hline \multirow{2}{*}{$\begin{array}{l}\text { Learning } \\
\text { objectives }\end{array}$} & Student & $28(12.7)$ & $22(10.0)$ & $14(6.3)$ & $100(45.4)$ & $56(25.4)$ & \multirow{2}{*}{$0.00008^{*}$} \\
\hline & Faculty & $12(23.0)$ & $16(30.7)$ & $2(3.8)$ & $12(23.0)$ & $10(19.2)$ & \\
\hline \multirow[t]{2}{*}{ Assessment } & Student & $5(2.2)$ & $15(6.8)$ & $13(5.9)$ & $113(51.3)$ & 74 (33.6) & \multirow{2}{*}{$0.01126^{*}$} \\
\hline & Faculty & $7(13.4)$ & $5(9.6)$ & $2(3.8)$ & $21(40.0)$ & $17(32.6)$ & \\
\hline \multirow{2}{*}{$\begin{array}{l}\text { Teaching } \\
\text { strategy }\end{array}$} & Student & $102(46.3)$ & $69(31.3)$ & $15(6.8)$ & $18(8.1)$ & $16(7.2)$ & \multirow{2}{*}{$0.00001^{*}$} \\
\hline & Faculty & $7(13.4)$ & $20(38.4)$ & $5(9.6)$ & $12(23.0)$ & $8(15.3)$ & \\
\hline \multirow{2}{*}{$\begin{array}{l}\text { Teaching/ } \\
\text { learning } \\
\text { hours per day }\end{array}$} & Student & $16(7.2)$ & $70(31.8)$ & $4(1.8)$ & $100(45.4)$ & 30 (13.6) & \multirow[b]{2}{*}{$0.04332^{*}$} \\
\hline & Faculty & $5(9.6)$ & $10(19.2)$ & $3(5.7)$ & $16(30.7)$ & $18(34.6)$ & \\
\hline \multirow{2}{*}{$\begin{array}{l}\text { Student- } \\
\text { centred } \\
\text { activity }\end{array}$} & Student & $95(43.1)$ & $55(25.0)$ & $23(10.4)$ & $22(10.0)$ & $25(11.3)$ & \multirow{2}{*}{$0.00868^{*}$} \\
\hline & Faculty & $13(25.0)$ & $16(30.7)$ & $4(7.6)$ & $12(23.0)$ & $7(13.4)$ & \\
\hline \multirow{2}{*}{$\begin{array}{l}\text { Learning } \\
\text { resources }\end{array}$} & Student & $62(28.1)$ & $78(35.4)$ & $15(6.8)$ & $45(20.4)$ & $20(9.0)$ & \multirow{2}{*}{0.1832} \\
\hline & Faculty & $10(29.2)$ & $20(38.4)$ & $4(7.6)$ & $9(17.3)$ & 9 (17.3) & \\
\hline
\end{tabular}

Note: ${ }^{*} P$ value is significant at $\leq 0.05$ 
Table 2: Major pitfalls reported by the students about the integrated curriculum

Major issues reported by the students $(n=220)$

The number of credit hours for a whole programme is too much.

There are too many courses.

The arrangements of courses need to be changed.

There are too many assessments.

There is no gap between the courses.

The learning/teaching hours are too long.

Some teaching tools are missing.

Some of the subject areas overlap across disciplines.

There is a bias in the assessment of self-directed learning by the staff members.

The learning objectives for each subject are too many.

Learning resources are not available.

Too few handout for lectures.
Number of students (\%)

34 (15.4)

187 (85.0)

24 (10.9)

131 (59.5)

34 (15.4)

92 (41.8)

47 (21.3)

156 (70.9)

65 (29.5)

86 (39.0)

Table 3: Major pitfalls reported by the faculty members about the integrated curriculum

\begin{tabular}{|c|c|}
\hline Major pitfalls reported by the faculty members $(n=52)$ & $\begin{array}{l}\text { Number of faculty } \\
\text { members (\%) }\end{array}$ \\
\hline Integration requires many types of equipment. & $45(86.5)$ \\
\hline It is not suitable for a large class. & $49(94.2)$ \\
\hline Many subject areas are missing. & $44(84.6)$ \\
\hline $\begin{array}{l}\text { All timetables are crowded with activities, and there is no spare time to make up } \\
\text { for missed classes or activities. }\end{array}$ & $34(65.3)$ \\
\hline There is limited cooperation among disciplines. & $30(57.6)$ \\
\hline Some subject areas cannot be covered fully in the allocated 50 minutes. & $36(69.2)$ \\
\hline It is more stressful than traditional learning. & $41(78.8)$ \\
\hline It requires more contact hours. & $21(40.3)$ \\
\hline $\begin{array}{l}\text { The students can pass the complete course even if they don't achieve the } \\
\text { minimum requirement in each discipline. }\end{array}$ & $23(44.2)$ \\
\hline The students can skip some disciplines depending upon their weight in the course. & $24(46.1)$ \\
\hline $\begin{array}{l}\text { The students can pass the programme without identifying his or her weaknesses in } \\
\text { specific disciplines. }\end{array}$ & $21(40.3)$ \\
\hline $\begin{array}{l}\text { More effort is needed to plan the large number of assessments and assessment } \\
\text { activity such as analysis of the exam and its results, including item analysis and } \\
\text { difficulty index. }\end{array}$ & $38(73.0)$ \\
\hline $\begin{array}{l}\text { The management of problem-based learning sessions may be tutor directed } \\
\text { depending upon his/her discipline. }\end{array}$ & $15(28.8)$ \\
\hline $\begin{array}{l}\text { The assessment of self-directed learning, in general, and problem-based learning } \\
\text { (in particular) by tutors or facilitators may entail some bias. }\end{array}$ & $17(32.6)$ \\
\hline $\begin{array}{l}\text { Some of the staff members did not implement their basic roles in self-directed } \\
\text { learning. }\end{array}$ & $19(36.5)$ \\
\hline There is dissatisfaction about the integration as a whole. & $20(38.4)$ \\
\hline
\end{tabular}




\section{DISCUSSION}

In the present study, the questionnaire data revealed all the major pitfalls in the implementation of the integrated curriculum from the viewpoint of the students, faculty and administrative members at ABSM. Some of the reported pitfalls are in agreement with the limitations of integration reported elsewhere (15): a lack of faculty experience with some teaching tools, their inability to play the role of a tutor, lack of support in the implementation of the integrated curriculum, difficulty in framing the timetable with the allotted number of teaching hours, additional burden on the faculty members and a lack of cooperation among disciplines (16).

In the present work, analysis of the students' responses revealed that they had an issue with the large number of assessments, the large number of learning objectives and the extensive activity hours per day. An investigation into their situation revealed that for each course, a student has to take at least one quiz, an OSPE/OSCE and a final exam. Furthermore, if a student missed any of the learning sessions on account of unavoidable circumstances, it resulted in loss of marks. The consecutive arrangement of the courses made it more stressful for the students, as compared to their counterparts in traditional learning schools, in which the students had a transitional period after school admission within which they could acclimatise themselves to the new learning environment and cope with any initial difficulties. This transition period is less developed in the integrated curriculum, in which students have to start with the course and be assessed within the first two weeks from the start of the programme. These observations are compatible with the studies of Enns et al. (7) and Chhabra et al. (8), who reported that the educational environment appears to be an important factor that affects the quality of life of a medical student. Therefore, based on the present findings as well as the previously reported ones, it seems that the learning objectives and outcomes in the integrated curriculum need to be made more concise in order to ensure that students have a good quality of life. The teaching strategy and tools must be modified, and electronic learning must be included to help reduce the long hours of learning and activity.

In the present work, most of the faculty members mentioned the following limitations: the integration is not suitable for a large class, lots of equipment is required, some subject areas are missing, the process is more stressful, there are too many assessments, the learning objectives cannot be met in the 50-minute lecture, the timetable is too crowded, and there is limited cooperation among disciplines. Analysis of these complaints revealed that both students and faculty members are of the opinion that the integration is stressful, the timetable is crowded, and the learning objectives are too many. Therefore, these factors may need to be given importance when creating a plan to improve the implementation of the integrated curriculum.

In this study, most faculty members reported that integration-based learning is not suitable for a large class. This needs to be given serious consideration, as the respondents included different faculty members from different schools and countries. To resolve this issue, a large class could be divided into small groups that must be further subdivided into several smaller groups, in accordance with the concept of team-based learning. With regard to missing subject areas, which was reported by 44 of the 52 faculty members, two solutions could be implemented in parallel: a compensation plan for the current student batch and an alternative plan for upcoming batches. The compensation plan could include the addition of condensed courses that cover the missing subject areas. These courses could be made available on an electronic platform or included in more relevant forthcoming courses with the appropriate teaching strategy. The second plan is to revise the course contents before the commencement 
of future batches to include the missing subjects.

One of the issues mentioned by the faculty members is limited cooperation among disciplines and overlapping of the learning objectives between disciplines. To address this issue, different departments must be fully informed about the benefits of integration and its effects on the teaching/ learning process. For this purpose, a committee formed by faculty members representing the whole discipline must be formed, and this committee could formulate the learning objectives and specify the objectives to be covered by each discipline. This will prevent the overlapping of learning objectives across disciplines. Moreover, specification of the learning objectives for each discipline will help the faculty members focus on the delivery of these specific objectives in the allocated 50 minutes without the need for extra contact hours. For example, a pathologist could be asked to focus on the morphology of the viral hepatitis virus (the gross and microscopic morphologies) and complications, a microbiologist could be asked to focus on the hepatitis viruses and their markers, and the epidemiology of hepatitis could be assigned to the community medicine departments.

The faculty members reported that in the integration-based model, the students can pass the full course without achieving the minimum requirements in each discipline and can choose to not focus on disciplines according to their weight in the course. This means that students could pass the programme without identifying their weaknesses for each discipline separately. This issue can be managed by analysis of the students' scores for each discipline, and making the minimum requirements for each discipline as a cut-off point for passing the course. For example, the score of a student in pathology, which is one of the subjects in the gastrointestinal course, would be added to the scores of the other subjects at the end of the year. If the student's score for pathology is less than the cut-off point (regardless of the scores for the other subjects), he or she must not be allowed to move on to the clinical courses.

With regard to the number of assessments, these can be cut down by holding cumulative exams for multiple courses at the end of the semester. The establishment of a question bank will make it easy to prepare the exam paper. Further, post-exam psychometric studies, such as item analysis and difficulty index can be done using recent software technology.

In the current study, some faculty members stated that the basic roles of self-directed learning are not fully implemented by some members. For example, the management of the problem-based learning session may be tutor-directed, depending on his/ her discipline. Moreover, there might be some bias in the assessment of self-directed learning, in general, and problem-based learning, in particular, by tutors. Faculty development programmes must also provide guidance for faculty members on dealing with the steps of self-directed learning. This also encompasses the role of the tutor in problem-based learning sessions and the application of strict criteria for assessing students in order to avoid tutor bias. These observations are similar to those of many previous studies (17-19).

Some of the faculty members, especially those who had spent a long time in traditional learning systems, expressed dissatisfaction towards the integration model. This resistance may be a result of difficulty in communication between the faculty members, as stated by Muller et al. (20). Moreover, with the new system, there is more pressure on the teachers with regard to understanding and learning the use of an extensive variety of learning resources and tools, as the simple repetitive lecture format of the traditional learning system is not very difficult to grasp or implement (9). This issue could be managed by trying to gradually introduce faculty to the integration model, including them in the formulation of the learning objectives, enrolling them 
in a faculty development programme, motivating them by assigning them the role of course coordinator, and encouraging cooperation through shared activities such as creating student assignments and formulating problem-based scenarios. These methods will help them become more cooperative, less resistant and productive. These proposed steps are in accordance with the hypothesis of Haramati et al. (21), who stated that curricular integration cannot succeed if the participants do not understand the "language of education." Besides, faculty leaders should place importance on motivation of the staff by appreciating them and providing opportunities for their progress, as supplementary training to become skilled educators could help from the innovation perspective (21).

The issues mentioned by the administrative staff members were the extra time required by the faculty, preparation for consecutive exams and student issues with recording the course. The addition of more trained faculty members and staff development programmes could help solve the issue of staff resistance. The integrative approach is a costive model as it contains a variety of instruction tools and their requirements $(18,22)$, and requires funding by more than one partner, other than the university. The situation and figures could be shared with community members and some stakeholders in the faculty committee in order to ask for support and raise more funds. Another solution is to have rotating shifts to deal with the long teaching hours and to not increase the working hours of the faculty
(23). Furthermore, introducing habitbased interventions to introduce changes in the workplace physical activity habits among academics and workers could make a difference (24).

Establishment of an exam committee formed by faculty employees and headed by one of the faculty will resolve the issue of the large number of exams and repetitive work (18). Finally, the introduction of a clear policy for student recording and the use of online software technology could resolve the students' recording problems.

Overall, the present findings indicate that ABSM needs a time-bound action plan to tackle all the issues and limitations of the integrated curriculum. A SWOT analyses of the findings may help to better analyse the current situation. Moreover, these drawbacks may also be present in other contexts; hence, these solutions might need to be globalised for them to benefit other medical schools with the integrated curriculum.

\section{CONCLUSION}

To conclude, the present findings point to the need for clear policy charts by school administration, the introduction of faculty development programmes, well-equipped teaching/learning rooms and learning resources. These recommendations could ensure that the integration programme is effective. In situations where such changes are not possible, a traditional learning-based model could be considered. 


\section{APPENDIX}

Questionnaire used in the current study (The questionnaire was fulfilled by students of all academic years).

\begin{tabular}{lcccccc}
\hline Item & $\begin{array}{c}\text { Strongly } \\
\text { satisfied } \\
(5)\end{array}$ & $\begin{array}{c}\text { Satisfied } \\
\text { (4) }\end{array}$ & $\begin{array}{c}\text { Neutral } \\
\text { (3) }\end{array}$ & $\begin{array}{c}\text { Dissatisfied } \\
\text { (2) }\end{array}$ & $\begin{array}{c}\text { Strongly } \\
\text { dissatisfied }\end{array}$ \\
\hline
\end{tabular}

\section{I: Students}

The number of credit hours for the programme is suitable for achieving the programme outcomes.

The curriculum contains a lot of courses that reflect the nature of the programme and the curriculum.

The courses are sequenced in an appropriate order and facilitate acquisition of knowledge and skills.

The learning objectives of the courses are clear and well defined.

The assessment includes many assessment tools with several quizzes, OSPE, OSCE, and final exams.

The teaching strategy includes a wide variety of tools that are suitable for the intended learning outcomes of the programme and courses.

The number of teaching/learning hours per day is suitable to achieve the outcomes.

Student-centred activity is clearly defined and mapped in the curriculum.

Learning resources were adequate and available when I needed them.

\section{II: Faculty member}

Integration required the involvement of many faculty members.

The integration model makes me more a tutor than a teacher.

I have enough experience with the integration to evaluate the integrated model in the current school.

I have gone through a faculty developmental programme to help me accommodate the integration model. 
(continued)

\begin{tabular}{ccccccc}
\hline Item & Strongly & Satisfied & Neutral & Dissatisfied & Strongly \\
satisfied & (2) & (4) & (3) & (2) & (1) \\
\hline
\end{tabular}

Lots of teaching tools and more equipment, facilities, and learning resources are required.

The integration model relies on small groups and is not suitable for large classes.

Some subject areas are difficult to fit within a particular course, so they may be missing.

The timetables are crowded with activity, and there is no spare time to cover some activities that might be missed for unavoidable reasons.

The courses allow the para-curriculum activity to be covered.

Cooperation among disciplines is acceptable, and allows for the accommodation of a high level of integration between interdisciplinary and multidisciplinary courses.

The time allocated for each teaching tool is in keeping with the topic being covered.

The work in the integration-based environment is more stressful than that in the traditional environment.

The number of credit hours for the programme and courses is suitable for achieving the programme and course outcomes.

The mode of assessment of the integrated approach is in keeping with the nature of the programme and courses.

In the integrated approach, the minimum requirement for each discipline is sharply defined, and the students can pass it only if they meet this requirement.

In the integrated approach, the students may concentrate more on a specific discipline over others, depending on the weight of the disciplines in that course. 
(continued)

Item

tem

\section{Strongly} satisfied

(5)

\section{Satisfied}

(4)

Neutral Dissatisfied
(3)

Strongly dissatisfied

(1)

The feedback for each student based on their achievements, strengths, and weaknesses in terms of the overall curriculum is closely monitored and communicated confidentially to each student.

More effort needs to go into planning the number of assessments and assessment activities such as analysis of the exam and their results, including item analysis and difficulty index.

The management of the problembased learning session may be tutor directed, depending upon his/her discipline.

There is some bias in the assessment of self-directed learning (in general) and problem-based learning (in particular) by the tutor or facilitators.

Some of the faculty members did not adhere to their basic roles in selfdirected learning.

\section{III: Administrative staff}

I am in line with the nature of the integration-based model and its environment.

I am trained through workshops held by my institute in the integration of the curriculum as a part of the administrative development programme.

I found that the integrated class needs more logistic material than the traditional class.

The daily work time is suitable with the daily activities of the curriculum.

There is a clearly defined and communicated policy and procedure for the students to deal with the administration. 
(continued)

\begin{tabular}{|c|c|c|c|c|c|}
\hline Item & $\begin{array}{l}\text { Strongly } \\
\text { satisfied } \\
\text { (5) }\end{array}$ & $\begin{array}{c}\text { Satisfied } \\
\text { (4) }\end{array}$ & $\begin{array}{c}\text { Neutral } \\
\text { (3) }\end{array}$ & $\begin{array}{c}\text { Dissatisfied } \\
\text { (2) }\end{array}$ & $\begin{array}{c}\text { Strongly } \\
\text { dissatisfied } \\
\text { (1) }\end{array}$ \\
\hline
\end{tabular}

The students can deal with the administration at ease, and there are no barriers in communication between the students and administrative employees.

What did you dislike most about the integrated curriculum?

What suggestions do you have for improvements in your programme at your institution? 


\section{REFERENCES}

1. Bloom BS, Engelhart MD, Furst EJ, Hill WH, Krathwohl DR. Taxonomy of educational objectives: the classification of educational goals. Handbook I: cognitive domain. New York: David McKay Company; 1956.

2. Brauer DG, Ferguson KJ. The integrated curriculum in medical education: AMEE guide no. 96. Med Teach. 2015;37(4):31222. https://doi.org/10.3109/0142159X.2014 .970998

3. Wilkerson L, Wimmers P, Doyle LH, Uijtdehaage $S$. Two perspectives on the effects of a curriculum change: student experience and the United States medical licensing examination, step 1. Acad Med. 2007;82(10 Suppl):S117-20. https://doi .org/10.1097/ACM.0b013e318141f4f0

4. Shankar PR, Balasubramanium R, Dwivedi NR, Nuguri V. Student feedback about the integrated curriculum in a Caribbean medical school. J Educ Eval Health Prof. 2014;11:23. https://doi.org/10.3352/jeehp .2014 .11 .23

5. Lam TP, Khoo US, Chan YS, Cheng YH, Lam KF. The first batch of graduates of a new medical curriculum in Asia: how their teachers see them. Med Educ. 2004;38:9806. https://doi.org/10.1111/j.1365-2929.2004 $.01910 . \mathrm{x}$

6. Thompson AR, Braun MW, O'Loughlin VD. A comparison of student performance on discipline-specific versus integrated exams in a medical school course. Adv Physiol Educ. 2013;37:370-6. https://doi .org/10.1152/advan.00015.2013

7. Enns SC, Perotta B, Paro HB, Gannam S, Peleias M, Mayer FB, et al. Medical students' perception of their educational environment and quality of life: is there a positive association? Acad Med. 2016;91(3):409-17. https://doi.org/10.1097/ ACM.0000000000000952
8. Chhabra S, Misra A, Shah S, Kole T. Survey of student perception of medical education environment among emergency medicine residents of an academic medical centre in Northern India. Int J Emerg Med. 2016;9(1):5. https://doi.org/10.1186/s12245016-0098-3

9. Quintero GA, Vergel J, Arredondo $M$, Ariza MC, Gómez P, Pinzon-Barrios AM. Integrated medical curriculum: advantages and disadvantages. J Med Educ Curric Dev. 2016;3:133-7. https://doi.org/10.4137/ JMECD.S18920

10. Atta IS, AlQahtani FN. Integrated pathology and radiology learning for a musculoskeletal system module: an example of an interdisciplinary integrated form. Adv Med Educ Pract. 2018;9:527-33. https://doi .org/10.2147/AMEP.S167692

11. Atta IS, AlQahtani FN. How to adjust the strategy of radiopathologic teaching to achieve the learning outcomes? Int J Med Sci Public Health. 2018;7(2):86-91. https://doi .org/10.5455/ijmsph.2018.1130015122017

12. Atta IS, AlQahtani FN, Alghamdi TA, Mankrawi SA, Alamri AM. Can pathology - teaching' strategy be affected by the students' learning style and to what extent the students' performance be affected? Glo Adv Res J Med Med Sci. 2017;6(11):296301.

13. Atta IS, AlQahtani FN. Matching medical student achievement to learning objectives and outcomes: a paradigm shift for an implemented teaching module. Adv Med Educ Pract. 2018;9:227-33. https:/doi .org/10.2147/AMEP.S158784

14. Likert R. A technique for the measurement of attitudes. Archives of Psychology. 1932;140: 1-55.

15. Dandannavar VS. Effect of integrated teaching versus conventional lecturing on MBBS phase I students. Recent Res Sci Technol. 2010;2(11):40-8. 
16. Joglekar S, Bhuiyan PS, Kishore S. Integrated teaching-our experience. J Postgrad Med. 1994;40:231-2.

17. Nosair E, Mirghani Z, Mostafa RM. Measuring students' perceptions of educational environment in the PBL program of Sharjah Medical College. J Med Educ Curric Dev. 2015;2015(2):71-9. https://doi.org/10.4137/JMECD.S29926

18. Shirani Bidabadi N, Nasr Isfahani A, Rouhollahi A, Khalili R. Effective teaching methods in higher education: requirements and barriers. J Adv Med Educ Prof. 2016;4(4):170-8.

19. Atta IS, Alqahtani FN. Hybrid PBL radiology module in an integrated medical curriculum Al-Baha Faculty of Medicine experience. J Contemp Med Edu. 2015;3(1):46-5. https://doi.org/10.5455/ jcme.20150525033016
20. Muller J, Jain S, Loeser H, Irby D. Lessons learned about integrating a medical school curriculum: perceptions of students, faculty and curriculum leaders. Med Educ. 2008;42(8):778-85. https://doi.org/10.1111/ j.1365-2923.2008.03110.x

21. Haramati A. Educating the educators: a key to curricular integration. Acad Med. 2015;90(2):133-5. https://doi.org/10.1097/ ACM.0000000000000444

22. Kadmon G, Schmidt J, De Cono N, Kadmon $M$. Integrative vs. traditional learning from the student perspective. GMS Z Med Ausbild. 2011;28(2):Doc28.

23. Anna C, Jane F, Andrew S. 21 hours: why a shorter working week can help us all to flourish in the 21 st century. London: New Economics Foundation; 2010.

24. Hamilton K, Fraser E, Hannan T. Habit-based workplace physical activity intervention: a pilot study. Occup Med (Lond). 2019;69(7):471-4. https://doi .org/10.1093/occmed/kqz1 19 